\title{
Oenococcus kitaharae sp. nov., a non-acidophilic and non-malolactic-fermenting oenococcus isolated from a composting distilled shochu residue
}

\author{
Akihito Endo and Sanae Okada \\ NODAl Culture Collection Center, Tokyo University of Agriculture, 1-1-1 Sakuragaoka, \\ Setagaya, Tokyo 156-8502, Japan
}

Correspondence
Akihito Endo
pegaman@hotmail.co.jp

\begin{abstract}
Six strains of lactic acid bacteria were isolated in Japan from a composting distilled shochu residue. The six isolates grew poorly on MRS agar and slowly in MRS broth. The 16S rRNA gene sequences did not show high levels of similarity to those of the recognized species of lactic acid bacteria, and formed a subcluster within the cluster comprising obligately heterofermentative lactic acid bacteria closely related to Oenococcus oeni. The levels of DNA-DNA relatedness revealed that the isolates belonged to the same taxon and were genetically separate from $O$. oeni. Furthermore, various phenotypic characteristics such as the optimum $\mathrm{pH}$ for growth, malolactic fermentation and resistance to $10 \%$ ethanol revealed that the isolates are distinguishable from O. oeni. On the basis of their phylogenetic and phenotypic characteristics, the isolates represent a novel species, for which the name Oenococcus kitaharae sp. nov. is proposed. The type strain is NRIC $0645^{\top}$ $\left(=\mathrm{JCM} 13282^{\top}=\mathrm{DSM} 17330^{\top}\right)$.
\end{abstract}

During a study of lactic acid bacteria originating from fermented plant material, six strains of lactic acid bacteria were isolated from a composting distilled shochu residue produced in Japan. Shochu is produced in Japan from rice, sweet potato, barley and other starchy materials fermented using Saccharomyces cerevisiae and Aspergillus niger, and is produced mainly in the southern Kyushu region (Endo \& Okada, 2005a). The composting represents an effective way of recycling the distilled shochu residue. The isolates grew poorly on MRS agar and slowly in MRS broth. A phylogenetic analysis based on 16S rRNA gene sequences revealed that the isolates formed a subcluster within the cluster comprising the heterofermentative lactic acid bacteria (Collins et al., 1991; Schleifer \& Ludwig, 1995), and were most closely related to Oenococcus oeni. The levels of DNA-DNA relatedness demonstrated that there was a clear separation between the novel isolates and O. oeni. Furthermore, the isolates possessed various phenotypic characteristics that could be used to distinguish them from O. oeni. This work deals with the taxonomic analysis of these six isolates and shows that they represent a novel species of the genus Oenococcus.

The novel strains, NRIC $0645^{\mathrm{T}}$, NRIC 0646, NRIC 0647, NRIC 0648, NRIC 0649 and NRIC 0650, were isolated from a composting distilled shochu residue produced in Miyazaki

The GenBank/EMBL/DDBJ accession number for the 16S rRNA gene sequence of strain NRIC $0645^{\top}$ is $A B 221475$.
Prefecture in the southern Kyushu area of Japan: the isolation was performed on MRS (Oxoid) agar containing $\left(1^{-1}\right)$ $10 \mathrm{mg}$ cycloheximide, $10 \mathrm{mg}$ sodium azide, $5 \cdot 0 \mathrm{~g}$ calcium carbonate and $15 \mathrm{~g}$ agar at $\mathrm{pH} 6.8$ and $30^{\circ} \mathrm{C}$. The strains formed very small colonies (less than $1 \mathrm{~mm}$ in diameter) on the MRS agar after incubation for 5 days. Colonies were picked and incubated in MRS broth $(\mathrm{pH} 6.8)$ at $30^{\circ} \mathrm{C}$. They grew slowly in the MRS broth, taking 4-5 days to reach the stationary phase. In MRS/tomato broth (MRS broth containing $10 \%$ filtered tomato juice; $\mathrm{pH} 6 \cdot 8$ ) they took 4-5 days to reach the stationary phase, and in MRS/BHI broth [half-strength MRS broth containing half-strength brain heart infusion (Eikenkizai) broth; $\mathrm{pH} \mathrm{6.8]} \mathrm{they} \mathrm{took}$ 3-4 days. Therefore the isolates were maintained in MRS/ BHI broth. O. oeni NRIC $0331^{\mathrm{T}}$ was obtained from the NODAI Culture Collection Center at Tokyo University of Agriculture, and was maintained in MRS broth containing $10 \%$ filtered tomato juice at $\mathrm{pH} 4 \cdot 8$ and $25^{\circ} \mathrm{C}$.

To determine the $16 \mathrm{~S}$ rRNA gene sequences of the isolates, DNA extraction, amplification, purification and sequencing were carried out as described previously (Endo \& Okada, 2005b). The closest recognized relatives of the isolates were determined by performing DataBase searches, and the sequences of closely related species were retrieved from the DDBJ database. Multiple alignments of the sequences were carried out with the program CLUSTAL_X, version 1.18 (Thompson et al., 1997). Distance matrices for the aligned sequences were calculated by using the two-parameter 
method of Kimura (1980). The neighbour-joining method was used to construct a phylogenetic tree (Saitou \& Nei, 1987). The robustness of individual branches was estimated by using bootstrapping with 1000 replicates (Felsenstein, 1985). To evaluate the topology of the phylogenetic tree, phylogenetic trees were also constructed by using the maximum-likelihood (Cavalli-Sforza \& Edwards, 1967) and maximum-parsimony (Kluge \& Farris, 1969) methods with PHYLIP version 3.65 (Felsenstein, 2005). Bootstrap values were determined by using the SEQBOOT program within the PHYLIP package. The 16S rRNA gene sequence (positions 8-1541) of strain NRIC $0645^{\mathrm{T}}$ and partial sequences (positions 8-531) of strains NRIC 0646, NRIC 0647, NRIC 0648, NRIC 0649 and NRIC 0650 were determined. Position numbers were based on the Escherichia coli numbering system (GenBank accession no. V00348; Brosius et al., 1981). The 16S rRNA gene sequence determined for strain NRIC $0645^{\mathrm{T}}$ was used to search for sequence similarity with DataBase, and approximately 1450 bp of the $16 \mathrm{~S}$ rRNA gene sequences of strain NRIC $0645^{\mathrm{T}}$ and related species were used to construct a phylogenetic tree. The highest level of sequence similarity to strain NRIC $0645^{\mathrm{T}}$ was found with $O$. oeni strains $(96.0 \%)$. In particular, the similarity of a partial sequence of strain NRIC $0645^{\mathrm{T}}$ [positions 8-531, containing the V1-V3 region (Van de Peer et al., 2000)] with respect to that of O. oeni was less than $93 \%$. This may be related to differences in the 16S rRNA secondary structures of these regions. The similarities for strain NRIC $0645^{\mathrm{T}}$ with respect to Leuconostoc species and Weissella species were $82 \cdot 8-85 \cdot 5$ and $82 \cdot 8-84 \cdot 7 \%$, respectively. Partial sequences (positions $8-531$ ) of the $16 \mathrm{~S}$ rRNA gene were determined for strains NRIC 0646, NRIC 0647, NRIC 0648, NRIC 0649 and NRIC 0650; these partial sequences were identical to each another and to that of strain NRIC $0645^{\mathrm{T}}$ (positions 8-531). Strain NRIC $0645^{\mathrm{T}}$ formed a subcluster within the cluster comprising the obligately heterofermentative lactic acid bacteria (Collins et al., 1991; Schleifer \& Ludwig, 1995), and were most closely related to $\mathrm{O}$. oeni on the basis of a neighbourjoining analysis (Fig. 1). Identical tree topologies were obtained using the maximum-parsimony and maximumlikelihood methods (data not shown).

The levels of DNA-DNA relatedness between the isolates and O. oeni NRIC $0331^{\mathrm{T}}$ were determined, and the DNA $\mathrm{G}+\mathrm{C}$ contents were determined for the isolates. The extraction and isolation of bacterial DNAs were performed by using the method of Marmur (1961) as modified by Ezaki et al. (1983). DNA-DNA hybridization was carried out by using the microdilution well technique, with photobiotin for labelling of the DNA (Ezaki et al., 1989). The G+C contents of the strains tested were determined by HPLC as described by Tamaoka \& Komagata (1984). The isolates showed high levels of DNA-DNA relatedness (90-100 \%) to one another. Therefore, we concluded that the isolates belonged to the same taxon. In contrast, the isolates showed low levels of DNA-DNA relatedness $(25-30 \%)$ to O. oeni NRIC $0331^{\mathrm{T}}$. The $\mathrm{G}+\mathrm{C}$ contents of the isolates ranged from 41 to $43 \mathrm{~mol} \%$.

To differentiate the isolates, randomly amplified polymorphic DNA (RAPD) fingerprinting was performed. DNA extraction was carried out by using a method described previously (Endo \& Okada, 2005b). RAPD PCR was performed according to the methods of Akopyanz et al. (1992) and Morotomi et al. (2002), using three primers (D, 5'-GAGGACAAAG; E, 5'-GGCGTCGGTT; and F, 5'GGCCACGGAA). The PCR products were subjected to $1.5 \%$ agarose gel electrophoresis. The gels were stained with ethidium bromide and photographed under UV light. The fingerprinting indicated that the isolates were genetically different from one another (Fig. 2).

Morphological, physiological and biochemical characteristics were determined by using methods described previously (Endo \& Okada, 2005b), but MRS/BHI broth was used as a basal medium. In addition, the decarboxylation of L-malate to L-lactate (malolactic fermentation) was determined by assessing the degradation of L-malate by using HPLC, as described by lino et al. (2001). The detailed

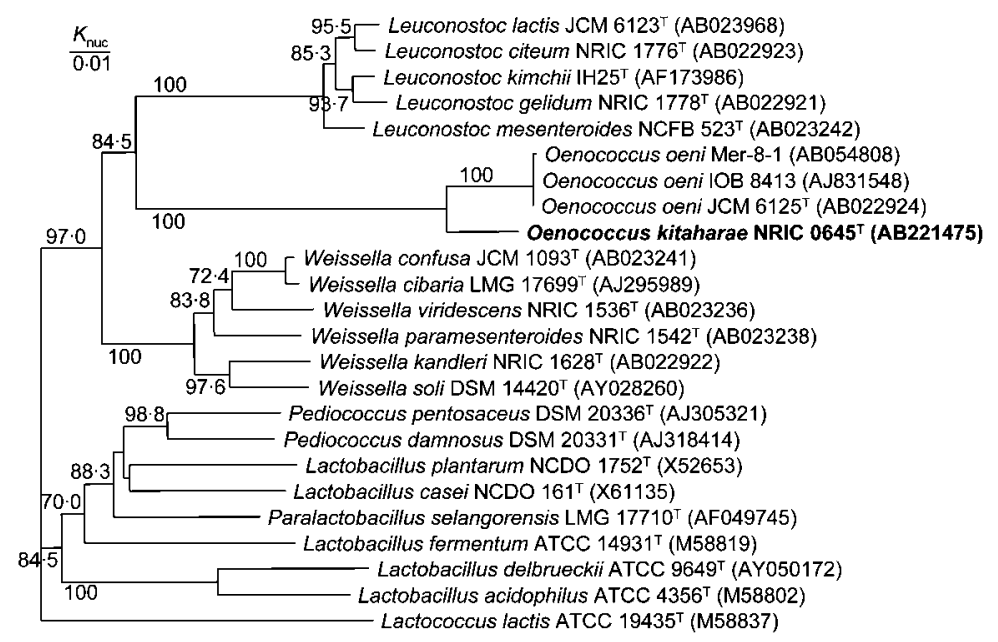

Fig. 1. Neighbour-joining phylogenetic tree showing relationships between strain NRIC $0645^{\top}$ and related taxa on the basis of $16 \mathrm{~S}$ rRNA gene sequences. Lactococcus lactis ATCC $19435^{\top}$ was used as an outgroup. Bootstrap percentages above $70 \%$ are given at branching points. 


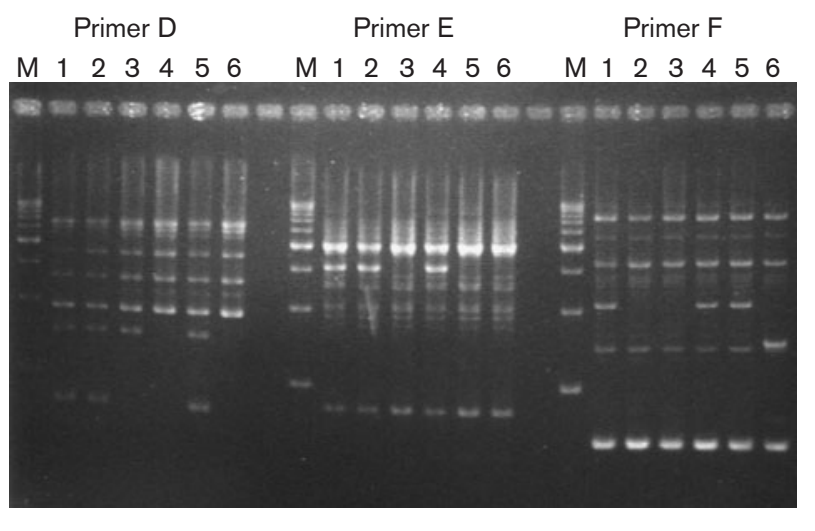

Fig. 2. RAPD PCR fingerprinting of the six novel isolates. Primers $D, E$ and $F$ were used (see text for details). Lanes: $M$, size marker (500 bp DNA ladder, Takara Bio); 1, NRIC 0645 ${ }^{\mathrm{T}}$; 2, NRIC 0646; 3, NRIC 0647; 4, NRIC 0648; 5, NRIC 0649; 6, NRIC 0650.

characteristics of the isolates are presented in the species description and Table 1 . They formed small colonies $(1 \mathrm{~mm}$ in diameter) on MRS/BHI agar after incubation for 7 days and formed very small colonies (less than $1 \mathrm{~mm}$ in diameter) on MRS agar after incubation for 7 days under aerobic conditions; they formed large colonies $(2 \mathrm{~mm}$ in diameter) on both media under anaerobic conditions in anaerobic jars (GasPak System; BBL) after incubation for 5 days. The isolates produced D-lactic acid, carbon dioxide and ethanol or acetic acid from D-glucose. This is consistent with $O$. oeni. However, the isolates were not acidophilic (they grew well at $\mathrm{pH} 6 \cdot 0-6 \cdot 8$ ), they did not perform malolactic fermentation and they did not grow in broth containing $10 \%(\mathrm{v} / \mathrm{v})$ ethanol; these characteristics clearly distinguished the isolates from O. oeni (Table 1).

On the basis of $16 \mathrm{~S}$ rRNA gene sequence analysis, the six isolates can be assigned to the genus Oenococcus, but the levels of DNA-DNA relatedness and the phenotypic characteristics indicated a clear separation of the isolates from the recognized species of the genus Oenococcus. Thus, the isolates represent a novel species, for which the name Oenococcus kitaharae sp. nov. is proposed. Furthermore, as some characteristics of $O$. kitaharae sp. nov. do not conform to those of the genus Oenococcus (Dicks et al., 1995), an emended description of the genus Oenococcus is also presented.

\section{Emended description of Oenococcus Dicks et al. 1995}

Oenococcus (Oe.no.coc'cus. Gr. n. oinos wine; N.L. masc. n. coccus from Gr. masc. n. kokkus berry; N.L. masc. n. Oenococcus coccus from wine).

The description of the genus Oenococcus is as given in detail by Dicks et al. (1995) with the following changes. Acidophilia, malolactic fermentation, growth in broth containing $10 \%(\mathrm{v} / \mathrm{v})$ ethanol and growth stimulation by substances in tomato juice are dependent on species. The DNA G $+\mathrm{C}$ content ranges from 37 to $43 \mathrm{~mol} \%$. The type species is Oenococcus oeni.

\section{Description of Oenococcus kitaharae sp. nov.}

Oenococcus kitaharae (ki.ta.ha' rae. N.L. gen. n. kitaharae of Kitahara, to honour the Japanese microbiologist Kakuo Kitahara, for his contribution to the systematics and classification of lactic acid bacteria and in the development of the study of lactic acid bacteria).

Cells are Gram-positive, non-motile and small ellipsoidal cocci measuring $0 \cdot 2-0 \cdot 4$ by $0 \cdot 5-0 \cdot 8 \mu \mathrm{m}$. Cells usually occur in pairs. Facultatively anaerobic and catalase-negative. Growth on agar medium is enhanced under anaerobic conditions. Colonies are white, smooth and approximately $1 \mathrm{~mm}$ in diameter on MRS/BHI agar and less than $1 \mathrm{~mm}$ in diameter on MRS agar under aerobic conditions after incubation for 7 days at $30^{\circ} \mathrm{C}$. However, on both media, colonies grown under anaerobic conditions are approximately $2 \mathrm{~mm}$ in diameter after incubation for 5 days at $30^{\circ} \mathrm{C}$. They are heterofermentative and produce lactic acid, carbon dioxide and ethanol or acetic acid from D-glucose. D-Lactate and L-lactate are produced in the ratio 9:1. Nitrate is not reduced. Acid is produced from D-glucose, D-fructose, D-galactose, D-mannose, maltose, melibiose and D-trehalose and produced weakly from D-ribose, D-gluconate and raffinose, but not from L-arabinose, D-xylose, L-rhamnose, lactose, sucrose, D-melezitose, D-mannitol, D-sorbitol or starch. Acid production from cellobiose and

Table 1. Differential characteristics of strain NRIC $0645^{\top}$ and O. oeni

Data for O. oeni strains are from Garvie (1967) and Dicks et al. (1995).

\begin{tabular}{|lcc|}
\hline Characteristic & Strain NRIC $\mathbf{0 6 4 5}^{\mathbf{T}}$ & O. oeni \\
\hline Growth in broth containing $10 \%$ ethanol & - & + \\
Malolactic fermentation & - & + \\
Optimum pH for growth & $6 \cdot 0-6 \cdot 8$ & $4 \cdot 8$ \\
Optimum temperature for growth & 30 & 22 \\
Acid from maltose & + & - \\
\hline
\end{tabular}


D-salicin is strain-dependent. Dextran is not formed from sucrose. L-Malate is not decarboxylated to L-lactate in the presence of a fermentable carbohydrate. Cells grow between 20 and $30^{\circ} \mathrm{C}$ but not at 15 or $37^{\circ} \mathrm{C}$. The optimum temperature for growth is $30^{\circ} \mathrm{C}$. All strains grow at $\mathrm{pH}$ values ranging from $5 \cdot 0$ to $7 \cdot 5$; some strains grow at $\mathrm{pH} 4 \cdot 5$. The optimum $\mathrm{pH}$ for growth is between $6 \cdot 0$ and $6 \cdot 8$. Growth is not stimulated in the presence of tomato juice. Growth is observed in MRS/BHI broth containing $1 \%(\mathrm{w} / \mathrm{v}) \mathrm{NaCl}$ but not $2.5 \%(\mathrm{w} / \mathrm{v}) \mathrm{NaCl}$. Growth is also observed in broth containing $5 \%(\mathrm{v} / \mathrm{v})$ ethanol but not $10 \%(\mathrm{v} / \mathrm{v})$ ethanol. The DNA G $+\mathrm{C}$ content ranges from 41 to $43 \mathrm{~mol} \%$ (type strain, $41 \mathrm{~mol} \%)$.

The type strain is NRIC $0645^{\mathrm{T}}\left(=\mathrm{JCM} 13282^{\mathrm{T}}=\mathrm{DSM}\right.$ $\left.17330^{\mathrm{T}}\right)$. All known strains were isolated in 2003 from a composting distilled shochu residue collected at a shochu distillery in Miyazaki Prefecture in the southern Kyushu area of Japan.

\section{Acknowledgements}

We thank the owner and staff of Akashi Distillery Ltd, Miyazaki, Japan, for providing the fermentation samples. We also thank K. Komagata for valuable discussions and N. Tanaka (Center for Information Biology and DNA Database of Japan, National Institute of Genetics, Shizuoka) for advice regarding the construction of phylogenetic trees using maximum parsimony and maximum likelihood. We are also grateful to R. Tsuji and J. Iida (NODAI Culture Collection Center, Faculty of Applied Bioscience, Tokyo University of Agriculture) for their technical assistance.

\section{References}

Akopyanz, N., Bukanov, N., Westblom, T. U., Kresovich, S. \& Berg, D. E. (1992). DNA diversity among clinical isolates of Helicobacter pylori detected by PCR-based RAPD fingerprinting. Nucleic Acids Res 20, 5137-5142.

Brosius, J., Dull, T. J., Sleeter, D. D. \& Noller, H. F. (1981). Gene organization and primary structure of a ribosomal RNA operon from Escherichia coli. J Mol Biol 148, 107-127.

Cavalli-Sforza, L. L. \& Edwards, A. W. F. (1967). Phylogenetic analysis models and estimation procedures. Am J Hum Genet 19, 233-257.

Collins, M. D., Rodrigues, U. M., Ash, C., Aguirre, M., Farrow, J. A. E., Martinez-Murcia, A., Philips, B. A., Williams, A. M. \& Wallbanks, S. (1991). Phylogenetic analysis of the genus Lactobacillus and related lactic acid bacteria as determined by reverse transcriptase sequencing of 16S rRNA. FEMS Microbiol Lett 77, 5-12.

Dicks, L. M. T., Dellaglio, F. \& Collins, M. D. (1995). Proposal to reclassify Leuconostoc oenos as Oenococcus oeni [corrig.] gen. nov., comb. nov. Int J Syst Bacteriol 45, 395-397.
Endo, A. \& Okada, S. (2005a). Monitoring the lactic acid bacterial diversity during shochu fermentation by PCR-denaturing gradient gel electrophoresis. J Biosci Bioeng 99, 216-221.

Endo, A. \& Okada, S. (2005b). Lactobacillus satsumensis sp. nov. isolated from mashes of shochu, a traditional Japanese distilled spirit made from fermented rice and other starchy materials. Int J Syst Evol Microbiol 55, 83-85.

Ezaki, T., Yamamoto, N., Ninomiya, K., Suzuki, S. \& Yabuuchi, E. (1983). Transfer of Peptococcus indolicus, Peptococcus asaccharolyticus, Peptococcus prevotii, and Peptococcus magnus to the genus Peptostreptococcus and proposal of Peptostreptococcus tetradius sp. nov. Int J Syst Bacteriol 33, 683-698.

Ezaki, T., Hashimoto, Y. \& Yabuuchi, E. (1989). Fluorometric deoxyribonucleic acid-deoxyribonucleic acid hybridization in microdilution wells as an alternative to membrane filter hybridization in which radioisotopes are used to determine genetic relatedness among bacterial strains. Int J Syst Bacteriol 39, 224-229.

Felsenstein, J. (1985). Confidence limits on phylogenies: an approach using the bootstrap. Evolution 39, 783-791.

Felsenstein, J. (2005). PHYLIP (phylogeny inference package), version 3.6. Distributed by the author. Department of Genome Sciences, University of Washington, Seattle, USA.

Garvie, E. I. (1967). Leuconostoc oenos sp. nov. J Gen Microbiol 48, 431-438.

lino, T., Manome, A., Okada, S., Uchimura, T. \& Komagata, K. (2001). Effects of sodium acetate on the production of stereoisomers of lactic acid by Lactobacillus sakei and other lactic acid bacteria. J Gen Appl Microbiol 47, 223-239.

Kimura, M. (1980). A simple method for estimating evolutionary rates of base substitutions through comparative studies of nucleotide sequences. J Mol Evol 16, 111-120.

Kluge, A. G. \& Farris, J. S. (1969). Quantitative phyletics and the evolution of the anurans. Syst Zool 18, 1-32.

Marmur, J. (1961). A procedure for the isolation of deoxyribonucleic acid from microorganisms. J Mol Evol 3, 208-218.

Morotomi, M., Yuki, N., Kado, Y., Kushiro, A., Shimazaki, T., Watanabe, K. \& Yuyama, T. (2002). Lactobacillus equi sp. nov., a predominant intestinal Lactobacillus species of the horse isolated from faeces of healthy horses. Int J Syst Evol Microbiol 52, 211-214.

Saitou, N. \& Nei, M. (1987). The neighbor-joining method: a new method for reconstructing phylogenetic trees. Mol Biol Evol 4, 406-425.

Schleifer, K. H. \& Ludwig, W. (1995). Phylogeny of the genus Lactobacillus and related genera. Syst Appl Microbiol 18, 461-467.

Tamaoka, J. \& Komagata, K. (1984). Determination of DNA base composition by reversed-phase high-performance liquid chromatography. FEMS Microbiol Lett 25, 125-128.

Thompson, J. D., Gibson, T. J., Plewniak, F., Jeanmougin, F. \& Higgins, D. G. (1997). The CLUSTAL_X windows interface: flexible strategies for multiple sequence alignment aided by quality analysis tools. Nucleic Acids Res 25, 4876-4882.

Van de Peer, Y., De Rijk, P., Wuyts, J., Winkelmans, T. \& De Watcher, R. (2000). The European small subunit ribosomal RNA database. Nucleic Acids Res 28, 175-176. 